\title{
José Checa, vir docto et facetus
}

\author{
Abraham Madroñal Durán \\ Université de Genève
}

José Checa Beltrán (Jamilena, Jaén, 1950) fue una de las primeras personas que conocí cuando llegué a la antigua sede del CSIC de Humanidades, en la ańorada calle de Medinaceli. A decir verdad lo conocía de antes, porque ambos teníamos un amigo común que nos había presentado, el pintor e ilustrador toledano Teo Puebla. Desde el principio me sorprendió su aspecto, que tendía más al de un joven de los sesenta, con su melena al viento, que a lo que yo imaginaba como un científico del Consejo. Otra cosa que me llamó poderosamente la atención fue su sinceridad a prueba de bombas.

Una vez desembarcado en el antiguo edificio del Centro de Estudios Históricos, pude disfrutar de su amistad durante todos los años de nuestra estancia allí y los que compartimos en el moderno edificio de la calle Albasanz. El doctor Checa me presentó a la gente del Centro de Ciencias Humanas y me incluyó en su equipo de investigadores: el grupo de Teoría Literaria. Después participaríamos del equipo de Literatura, imagen e Historia cultural, dentro del Instituto de la Lengua Española, primero, y luego del Instituto de Lengua, Literatura y Antropología.

Pronto empecé a admirar su curriculum vitae, pero más que el académico, el personal. Pepe, como quiere que se le llame, hubo de buscarse la vida para conquistar su estatus de científico titular y sucesivamente de investigador científico. Y no le resultó nada fácil. Llegado a Madrid desde su querida Jamilena en tiempos difíciles, me contó su periplo por pensiones diversas: aquellas que ofrecían habitación con cocina y baño compartidos. En una de ellas coincidió con el exsecretario general de la 
UGT, Cándido Méndez, que al parecer tenía la bendita costumbre de vaciar la nevera común sin reponer nunca su contenido.

En aquellos días, Pepe hizo un poco de todo: fue botones y empleado de banca, entre otras tareas, mientras estudiaba Filología Hispánica en la Universidad Complutense — se licenció en 1978 y se doctoraría diez años después-. Allí conoció a Pilar, compañera de curso y más tarde su mujer. Después de gozar de trabajo fijo en la banca — donde seguramente se ganaría el pan mucho mejor que con el Siglo de las Luces-, consiguió un puesto de becario de investigación de don Francisco Aguilar Piñal y no dudó en abandonar la seguridad de aquella vida por las estrecheces de la de becario. Como tal desarrolló una estancia en la Universidad de Bolonia, donde se doctoraría en Lenguas y Literaturas Extranjeras Modernas en 1986. El nacimiento de su hijo Luis, en Madrid, coincidió con su estadía en Italia y se vio obligado a soportar estoicamente una serie de meses para conocerlo.

Dicha precariedad, término que siempre ha rimado con el de becariedad, lo llevó, según propia confesión, a ser acogido en el piso de una amiga que poseía como única cama un ataúd. Es de imaginar a nuestro amigo levantándose cada mañana como si de allí saliera alguien que volviera a la vida.

Por fortuna, en su etapa boloñesa conoció a grandes maestros, como Rinaldo Froldi o Maurizio Fabbri, de los que siempre contaba maravillas. Ya de vuelta a Madrid, sufrió algún que otro desengaño antes de ganar su plaza en el CSIC. El bendito sistema de oposiciones dentro del mundillo académico español.

Pero ni siquiera tales reveses torcieron su bonhomía: el doctor Checa es, además de un querido camarada, uno de los mejores colegas que descubrí en el Centro de Ciencias Humanas y Sociales. Me hizo amigo de sus amigos —entre ellos el novelista Alfredo Gómez Cerdá—, me llevó a su casa de Humanes (Guadalajara) y también a la que por fin se compró en Jamilena, su pueblo natal, donde pensaba jubilarse. Me enrolé gracias a sus desvelos en varios proyectos de la Diputación Provincial de Jaén, para la que continúa siendo un intelectual de referencia. Con él presenté el primer número de su revista, Piedras lunares, amén de colaborar en la valoración del legado de Miguel Hernández, que recaló — quiero pensar que en parte gracias a nuestro informe- en dicho organismo y en el $\mathrm{Mu}$ seo de Quesada, el pueblo de su mujer. 
Sin embargo, toda esta semblanza quedaría lógicamente incompleta si no dijera que José Checa es un gran especialista en muchas cosas: particularmente en el siglo XVIII, pero también en teoría de la literatura, en el romancero - su Romancero oral de la comarca de Martos recibió el premio Cazabán de la Diputación de Jaén en 2004_- en los vínculos de las letras peninsulares con las galas, en la prensa ilustrada... e cosi via.

Se le deben libros emblemáticos como La poesía del siglo XVIII (1992), Razones del buen gusto. Poética española del Neoclasicismo (1998), Pensamiento literario del siglo XVIII español: antología comentada (2004), Lecturas del legado español en la Europa ilustrada (2012), Demonio y modelo (Dos visiones del legado español en la Francia ilustrada) (2014), El debate literario-politico en la prensa cultural española: 1801-1808 (2016) o el más reciente, dedicado a un notable intelectual dieciochesco: Antonio de Capmany: Luces y sombras (2020), donde despeja las sombras de este político liberal, que también fue destacado literato.

Tanta dedicación y modélica producción le condujeron a dirigir la prestigiosa Revista de Literatura del CSIC, después de haber sido su secretario durante lustros. La labor callada de Checa, en una época en que no había demasiadas ayudas a la edición y buena parte del carteo se hacía por correo ordinario, la desarrolló con rigor y ejemplaridad admirables. Me consta que, como secretario, asumía buena parte de la gestión, descargando al director de todo cuanto le era posible. Y también durante la etapa en que asumió el mando, para no sobrecargar entonces a su segundo. Así era José Checa y no ha cambiado un ápice.

Nuestro homenajeado acometió multitud de proyectos en el Centro de Ciencias Humanas, integrando dentro de ellos a un buen número de colegas del país y no pocos foráneos: El debate literario de la prensa madrileña en el umbral del Romanticismo, Sociedad y cultura en la prensa giennense (1941-1965), Lecturas del legado literario-cultural español: canon, nacionalismo e ideología en España, Francia e Italia (1700-1808) y Canon y nacionalismo: lecturas europeas del legado literario-cultural español (1788-1833). De todos se desprendieron coloquios y monografías que denotan la sabia mano del maestro.

Ha disfrutado también de varias estancias de investigación en la UNAM (México), en las universidades canadienses de Montreal y McGill, en la Sorbonne Nouvelle-Paris III y en la de Ginebra, junto a quien suscribe. 
Esta última la aprovechó para investigar los manuscritos dieciochescos de la Biblioteca de la Universidad, de los cuales yo había dado cuenta en un libro. Cuando quiso publicar aquellas pesquisas en los Cuadernos de Estudios del siglo XVIII (2018), se empeñó en que yo debía cofirmarlas; y ahí aparecemos los dos, a pesar de mis protestas. Rara avis en un ecosistema tan competitivo y cainita.

Checa nunca se endiosó como miembro del centro que lo acogía, ni siquiera a lo largo de su etapa como director de la Revista de Literatura, que le dio más trabajo que satisfacciones. Y cuando llegó el momento de la jubilación, tampoco sintió reparo en deshacerse de sus libros, que en parte se conservan hoy a la Biblioteca de Ginebra. Supongo que para él lo importante no residía en lo material, sino en los recuerdos y experiencias de aquellas décadas.

Me narraba muchas anécdotas de los científicos que había conocido: del bueno de Juan María Díez Taboada, su antecesor como secretario de la Revista de Literatura; de nuestro común amigo, también jienense y tocayo suyo, Pepe Torres; de la simpática bibliotecaria Sonsoles... Incluso de los que se ocupaban del mantenimiento del viejo edificio de Medinaceli. Las comidas con Checa y otros colegas de aquel inmueble eran de lo más placentero que uno podía llevarse a la boca en medio de una larga jornada de trabajo.

Como buen neoclásico, su despacho siempre estaba perfectamente ordenado, pero a la vez dominaba su mesa un sano revoltijo de papeles, manuscritos con esa letra tan particular. Jamás despreció un café ni un rato de amena conversación con el recién llegado; tampoco a ningún becario o visitante de toda índole — que eran muchos en la antigua sede y menos en la nueva_- De hecho, se hacía amigo de los más jóvenes, a los que procuraba ayudar, como a mí mismo o al revoltoso califa de la Bética.

Pepe no era, no es, un santo laico. Se conduce simplemente como un buen hombre y un investigador riguroso, amigo de sus amigos. He conocido a muy pocos de su talla, si bien estoy seguro de que le molestaría que se dijeran en público todas estas cosas. Como su admirado Capmany, Checa es también un liberal ilustrado y un gran filólogo que no se ha arrimado a los buenos para alcanzar la cumbre de toda buena fortuna. Por el contrario, siempre ha defendido más a los de abajo: becarios, científicos a 
la búsqueda de una plaza, estudiantes que se le acercaban para consultarle cualquier asunto...

Vir docto et facetus, podría ser la inscriptio de este emblemático sabio y hombre íntegro y entretenido que es José Checa. 